\title{
Review of evolution of clinical, training and educational services and research program for autism spectrum disorders in Hong Kong
}

\author{
Virginia Chun-Nei WONG ${ }^{*}$, Cheuk-Wing FUNG, So-Lun LEE \& Polly Tsz Yan WONG \\ Department of Paediatrics and Adolescent Medicine, the University of Hong Kong, Queen Mary Hospital, Hong Kong, China
}

\begin{abstract}
The evolution of a local fragmented model of services for children with autism in Hong Kong emerged gradually over the past three decades with lack of government funding or support. This had been due to increasing number of children with autism being detected and referred for earlier assessment. With increasing pressure from parents due to long waiting time for assessment and training services and the increasing polarization by mass media there had been a gradual increasing public awareness over the past five years. Though still highly fragmented in the availability of services, there is a growing "business model" available in the community due to increasing need and lack of public funding for support. There is a lack of strategic planning for medical diagnostic and management issues in Hong Kong. Our University of Hong Kong based Autism Research Program was pioneered in 1985 based on the increasing load of autism cases referred for assessment for other developmental problems and diagnosed as Autism in the Duchess of Kent Children's Hospital. As the first author has been the staff of the University of Hong Kong, this program flourished as a research based program. The benefits of early identification and intervention of autism spectrum disorder (ASD) had been increasingly recognized, and with the increased public awareness and increasing trend of earlier diagnosis, there has been a continuously high demand from parents for earlier assessment and training for children suspected to have ASD. This model had not received extra funding for this integrated program for research, teaching and training in autism. We had to apply for various donations and grants to support the development of this pioneer program. The research output and organization of forums for public education and awareness are reviewed. The latter part of the paper reports the summary of clinical profile of autism cases $(N=1441)$ assessed from 1985 to 2010 June under the University of Hong Kong. As the waiting time for initial developmental assessment for any children in Hong Kong is 12-24 months, we also report our preliminary experience with a newly launched triaging service provision for children suspected to be ASD since 2009, including multi-disciplinary assessment and parallel interim training in our university affiliated child assessment centre in Hong $(N=89)$.
\end{abstract}

autism spectrum disorder (ASD), autism, Asperger syndrome, children

Citation: Wong VCN, Fung CW, Lee SL, Wong PTY. Review of evolution of clinical, training and educational services and research program for autism spectrum disorders in Hong Kong. Sci China Life Sci, 2015, 58: 991-1009, doi: 10.1007/s11427-012-4294-y

\section{Introduction}

In 2004, we had published the "developmental milestones" of services for autism ${ }^{1)}$ over the past 20 years in Hong Kong

*Corresponding author (email: vcnwong@hku.hk)

1) Autism spectrum disorder (ASD) will be used interchangeably with "autism".
[1]. Since this report had been published, the situation has been similar with lack of government support except for increasing availability of training programs in the private sector. As parents are devastated to have their autistic children "treated" as early as possible and there is lack of universal standard of treatment guidelines, parents had been confused and might even be exploited with the so claimed 
intensive training with multiple programs available in the market. There is a lack of coordination, research or legislation concerning the "Best" model of training or educational services for autistic children.

In 1994, the Health and Welfare Bureau of Hong Kong adopted the 8-10 in 10000 prevalence rate of United Kingdom and estimated that there are around 6500 children in Hong Kong with autism (Working Group on Services for Autistic Persons-Health and Welfare Bureau). The Central Registry of Rehabilitation (CRR) had been actively collecting territory-wide data on self reported disabilities with a view to provide statistics on disabilities to government departments and non-governmental organizations for planning rehabilitation services and research purposes [2].

\subsection{Clinical services for autism in Hong Kong}

In the early 1960s-1980s, most cases of autism were under the care of adult psychiatrists. Services for autism were provided as for those with psychiatric or mental disorders. Most were labeled as for mentally handicapped persons. The subspecialty Paediatrics was gradually established in the mid-1960s, with subspecialties such as developmental pediatrics, child neurology and child psychiatry being established in the 1980s. These subspecialties were concerned in children with autism, and children with speech delay or behavioral problems were increasingly recognized and diagnosed as due to autism. Medical services for children with autism are available under the Hospital Authority as for any children with medical illness. In the 1980s, most autistic children were first referred to child psychiatrists. However, in the 1990s, most autistic children were referred to developmental pediatricians.

From birth to three years, developmental screening to detect all children with suspected developmental disabilities is undertaken in Maternal and Child Health Centers (MCHC) under Department of Health (DH). In 2004, developmental surveillance program gradually replaced developmental screening by phases. These children with developmental disabilities will be referred for comprehensive developmental assessment in Child Assessment Centers under Special Health Service, Department of Health (six CACs) [3] and Hospital Authority (HA) (Duchess of Kent CAC is the only CAC under HA).

\subsection{Development of training and educational services for autism in Hong Kong}

Public awareness for autism improved in the early 2000s with widespread reporting of accidents of autistic children from the mass media, e.g., a pair of aged parents lost contact of their only child who was a 12-year-old mentally retarded autistic boy on crossing the immigration counter to mainland China in the mid 1990s and this had driven the public to a care level for the family.

There has been a gradual but slow growth of services for autism within the framework of children with "developmental disabilities" (DD). Most of the public services available for children with developmental disabilities are provided by non government organizations (NGO). Parents of children with developmental disabilities like Down syndrome, mental retardation (or intellectual disabilities) and later autism began to organize self help groups. Most of the services are within the disciplines of speech therapists and occupational therapists with group or individual training.

\subsection{Training services}

Children with DD or autism are referred to preschool training programs under Social Welfare Department (SWD): Early Education \& Training Centers (EETC), Integrated Child Care Centers (ICCC) and Special Child Care Centers (SCCC), Integrated Program for Mildly Disabled Children in Kindergartens (IK/G) and Preparatory Class in Special School, or Occupational Therapy Department under HA. Other preschool services are provided by the Developmental and Support Services by Fu Hong Society [4].

\subsection{Educational services}

School services are provided under Education Department $\&$ Bureau (EDB). Children with autism who have IQ $<70$ are referred to special schools for mentally handicapped (MH) as for any children with intellectual disabilities (ID). There is "No" school designated for children with autism or Asperger syndrome.

All through the past four decades, there is little transition or continuity of care from early childhood through adulthood for people with autism as for any other medical conditions like congenital heart diseases.

\subsection{Early identification, diagnosis and management of children with autism in Hong Kong}

Services can be grouped into three stages: identification and diagnosis, assessment, and training/interventions.

\subsubsection{Early identification and diagnosis}

There is usually a time lag of 12-24 months between the onset, actual clinical presentation and referral. The waiting time for developmental assessment varied from 12-24 months for CAC.

\subsubsection{Developmental assessment by multi-disciplinary assessment team}

After screening, any children with suspected developmental disabilities will be referred to Child Assessment Centers (CAC) for comprehensive developmental and behavioral assessment. Currently, there are seven CAC in Hong Kong, 
with six centers under the Department of Health; and our center, the Duchess of Kent Child Assessment Center (DKCAC) [5], under the Hospital Authority. The assessment team provides rehabilitation for children with any developmental disabilities or autism. Members of the multidisciplinary team include child neurologist, developmental pediatrician, clinical psychologist, speech therapist, occupational therapist, physiotherapist, audiologist, optometrist, medical social worker and nurses. For children with autism, management also involves other specialists such as child psychiatrists. CAC also provides therapy and parental support.

The Duchess of Kent Child Assessment Center (DKCAC) was pioneered in 1985 for early assessment of any children with neurodevelopmental disabilities. This was inaugurated in 1987 under the Department of Pediatrics of the University of Hong Kong; and under the Hospital Authority since 1990. Our Center was started as the second Child Assessment Center after the establishment of the first Child Assessment Center (CAC) by the Department of Health in 1975. Our DKCAC is more targeted on research based training and clinical services. We had pioneered the first integrated Tripartite Program of Child Neurology/Developmental Pediatrics/Neurohabilitation, especially for autism based in the University of Hong Kong [6].

\subsubsection{Training/intervention services}

The training services in Hong Kong can be classified into pre-school training services, school-age special education and private training centers[7].

(i) Preschool age (2-6 years). Specialized Autism Training Program developed by NGOs, e.g., Heep Hong Society [8], the Spastics Association of Hong Kong (SAHK) [9], and Caritas Rehabilitation Service [10]. The Hospital Authority also provides occupational therapy and speech therapy interim training for children who are awaiting full time placements.

(ii) School age (7-16 years). We do not have a local school to educate children with autism. These autistic children received education with other children with mental handicap. Over the years, there have been additional resource teachers employed in these special schools to help autistic children. There is, at present, no uniform approach in the educational program for autistic school children. The Child and Adolescent Mental Health Community Support Project [11] is supported under the Social Welfare Department and HA to provide early identification and early intervention services to children to children and adolescents with mental health problems with primary service targets towards children and adolescent aged 6 to 18 .

\section{6 "Business model" for autism services in Hong Kong}

Due to the increasing number of children diagnosed with autism over the past five years and there is a long waiting list for community training services organized by the NGO, many therapists started up private services as self financed services for autism. Some private speech therapists or clinical psychologists started to establish private schools for children with autism. However, there is lack of training of frontline staff to provide the technique for a disorder as heterogeneous as autism. Thus, parents are so desperate that they sought help from as many resources as possible based on information provided by the Internet and advertisement. Most of this information is not evidenced based. The financially better off parents support each other by sharing the travelling and hotel expenses of getting overseas ABA therapists as far back as 10 years ago.

There is a lack of standardization of training services and the standard of training varied with individual therapists or groups. Parents are usually at a lost after the clinical suspicion of autism is made and they will shop around for training services as the public services had been limited (Table 1). The financial burden to the autistic family especially when most of these parents shopped around for complementary and alternative medicine or therapy (CAM) creates an immediate challenge for the pediatrician to give the best and most updated evidence based information concerning autism for the families.

In the recent few years, there are several private care training and therapy centers available, including (but not limited to): iCare (Voice and Speech Therapy Centre) [12], Autism Partnership HK [13] (providing assessment and consultation), Whole Person Development Institute-iCan [14], and New PAGE Learning \& Developmental Consultants [15].

\subsection{Services for Asperger syndrome}

Children with Asperger syndrome have been under-recognized by most medical disciplines as were not taught 1 about this condition in our medical curriculum. Asperger children are usually mishandled by school teachers as they were not aware of this entity as well. These children usually manifested as school problems with behavioral issues or learning disabilities and earlier referral for a medical doctor to make the correct clinical diagnosis with team based medical-educational management is essential to prevent further psychological burden to the child. Unfortunately, we do not have specialized programs for children with Asperger syndrome. These children still attend normal school, and parents seek assistance through support groups. In 2004, the Project Aspire is launched to assist children with Asperger syndrome to strengthen their social and communication skills [16]. However, the sustainability of this limited service depends on funding and manpower.

\subsection{Psychosocial support network}

Over the years with increasing demand for training services 
Table 1 Examples of some self-financing program for autistic children in Hong Kong (payment in Hong Kong dollars)

\begin{tabular}{|c|c|c|}
\hline Year & Types of services & Details \\
\hline 1984 & Caritas Hong Kong & $\begin{array}{l}\text { Program: Comprehensive Training Program for Autistic Children } \\
\text { Individual: } \$ 200 / 45 \text { min (therapist); } \$ 130 / 45 \text { min (child care worker) } \\
\text { Pre-school Children Group Training: } \$ 130 / \text { session; } 8-9 \text { sessions } \\
\text { P.1 Adjustment Group: } 10 \text { sessions } \\
\text { Primary School Age Social Group: } \$ 130 / \text { session }\end{array}$ \\
\hline 1995 & $\begin{array}{l}\text { Louis Program Training Center } \\
\text { (Developed in } 1995 \text { by Mrs. } \\
\text { Yolanda Wong) }\end{array}$ & $\begin{array}{l}\text { 6-session training program for parents (no age limit) } \\
\text { Fee: Parents: } \$ 600 \text {; Professionals: } \$ 1200\end{array}$ \\
\hline \multirow[t]{3}{*}{2001} & $\begin{array}{l}\text { Salvation Army-Family Support } \\
\text { Services for Persons with Autism }\end{array}$ & $\begin{array}{l}\text { Home-Based Training Program } \\
1 \text { assessment }+16 \text { sessions (Fee: } \$ 940-\$ 4440) \\
\text { Workshops for Parents: early diagnosed cases; } \$ 800-\$ 3300 \\
\text { Training Groups: social skills, art therapy, sensory integration therapy, etc. } \\
6-10 \text { session }\end{array}$ \\
\hline & $\begin{array}{l}\text { Neighborhood Advice-Action } \\
\text { Council }\end{array}$ & $\begin{array}{l}\text { Practice, Research \& Training Center on Autism (PRTA) Wanchai, HK } \\
\text { Offers private screening for children aged } 18 \text { months to } 5 \text { years old who are showing signs of au- } \\
\text { tism and related communication delays } \\
\text { Self-financed unit } \\
\text { Offers one-stop access to a range of autism-related services, including comprehensive assessment, } \\
\text { treatment, family counseling/support }\end{array}$ \\
\hline & $\begin{array}{l}\text { Rainbow Project } \\
\text { (English Service) }\end{array}$ & $\begin{array}{l}5 \text { Day Program (TEACCH\&ABA (2 classes)) } \\
-\quad \text { age } 4-11 ; \text { capacity: } 7 \\
\text { Saturday Program (Social Play Group) } \\
\text { Summer Program (6 weeks) } \\
\text { Fee: } \$ 10540\end{array}$ \\
\hline 1994 & Springboard Project & $\begin{array}{l}\text { Primary Class: age } 5-11 \text {; capacity: } 12 \\
\text { Secondary Class: age } 11-16 \\
\text { Life Skills Class: age } 15-18 \\
\text { Fee: } \$ 17000 / \text { month }\end{array}$ \\
\hline
\end{tabular}

which are not met by government or other voluntary agencies, different parent associations and support groups have been formed in Hong Kong for children with developmental disabilities, autism and Asperger syndrome such as Society for the Welfare of the Autistic Persons (SWAP) [17], the Autism Hong Kong [18], Hong Kong Autism Awareness Alliance [19], the Parent Association of Autistic Children in Mainstream Ed (PAACME) [20], the Parent's Association of Pre-School Handicapped Children [21], the Salvation Army's Family Support Service for Persons with Autism [22], and Intellectually Disabled Education and Advocacy League (IDEAL) [23].

\subsection{Pioneer model of multi-disciplinary management model of the university based autism research program}

Our university-based program has been built up gradually and serves as a model of an integrated center for research, teaching and training program for autism. A multi-disciplinary management model has been established in the Duchess of Kent Child Assessment Center (DKCAC). Our autism research program evolved gradually with the goal of improvement in the rate of early detection, diagnosis, and intervention for autism through research-based programs. However, there had been lack of research or government services funding support for this program and we had to resort for donations to organize activities for these children (Figure 1).

\subsection{The Duchess of Kent Child Assessment Center (DKCAC) model program}

During each assessment session, the dual role of the child neurologist/developmental pediatrician is to obtain a comprehensive history and perform neurodevelopmental examination and behavioral assessment. Several diagnostic tools are used. We use the Griffiths Mental Developmental Scale [24] for assessment of the overall developmental profile. "Symbolic Play Test" [25] is another tool for assessment of language comprehension. As for diagnosis of autism spectrum disorders, we have been using different diagnostic instruments such as DSM-IV [26] and the Childhood Autism Rating Scale [27]. Since 2000, we have started using the Autism Diagnostic Interview-Revised [28] and in 2007, we have started using the Autism Diagnostic Observation Schedule [29] as part of the diagnostic evaluation. In 2009, we had started to use 3Di as part of the interview process. Our clinical psychologists will perform psychological/behavioral assessment. Physiotherapists will assess the gross motor function. Occupational therapists will assess fine motor function, visual-spatial, visual-perceptual aspect and plan for possible sensory integration program. Speech therapists will assess language and oral-motor function. Optometrists and audiologists will evaluate visual and hearing function. Medical social workers assess the psychosocial and financial aspects of the family, co-ordinate application of entry into various institutions involved in the training and education of children. Our center will provide 


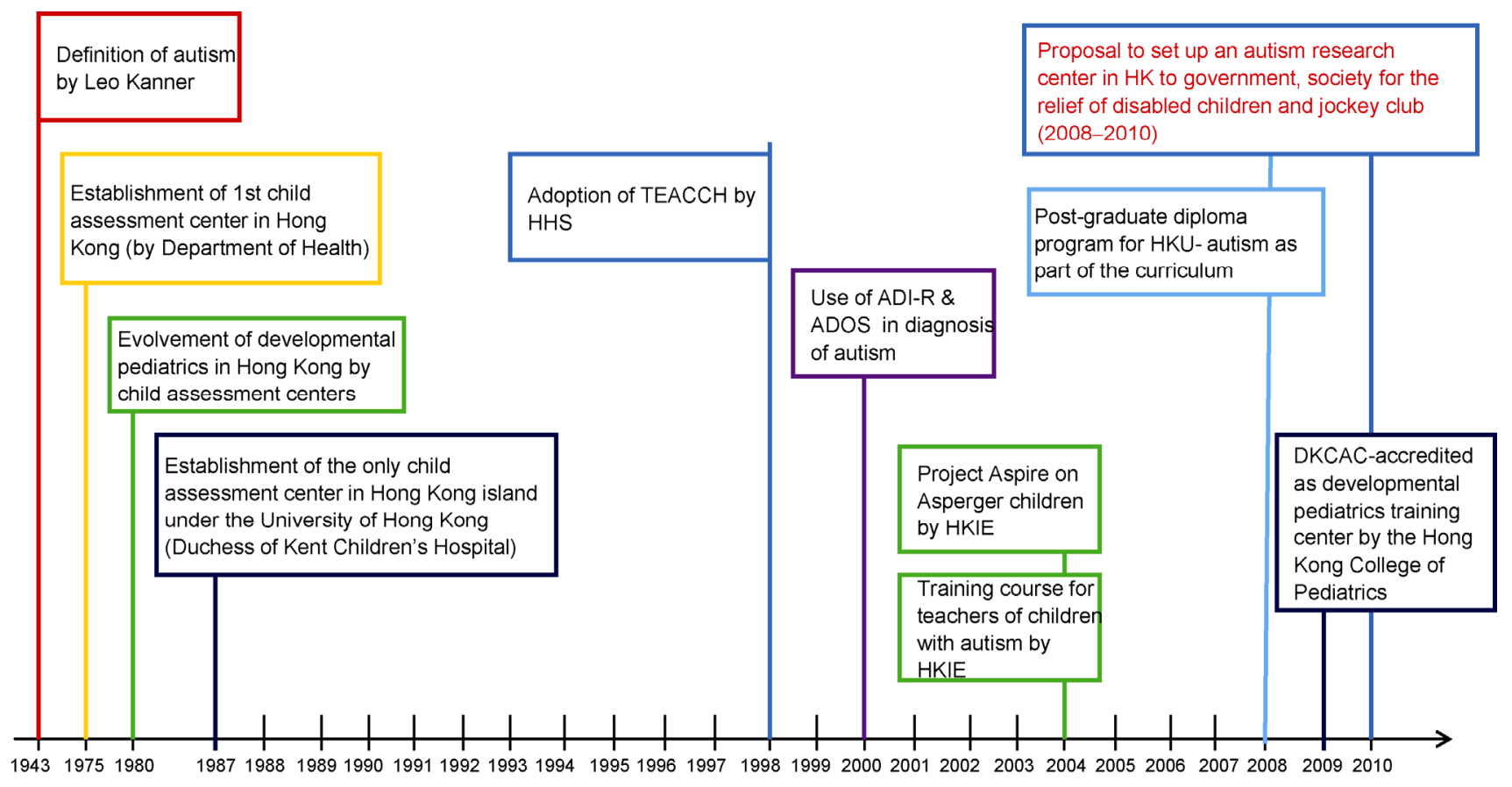

Figure 1 Time line showing the milestones of developing services for children with autism spectrum disorder in Hong Kong as of July 2010: evolution of autism services in Hong Kong.

therapy and training for selected children; developmental guidance, counseling and support for parents, and referral to appropriate agencies for medical, developmental, educational and social services.

\subsection{Screening for autism}

Screening tool for Chinese children with autism 18-24 months (2002-2003): In 2002-2003, we performed a pilot research study of adopting a screening instrument for early detection of Autism for children aged 18-24 months. We translated and merged two screening instruments for autism, i.e., "Checklist for Autism in Toddlers (CHAT)" for children aged 18 months in UK [30] and "Modified Checklist for Autism in Toddlers (M-CHAT)" for children aged 24 months in USA [31] to use for Chinese children. We have validated this new Chinese screening instrument for early detection of autism in Chinese by using 23 questions and four observation items, i.e., CHAT-23. Research on the applicability of this Chinese screening instrument for autism had been conducted in Fudan University, Shanghai, China, and practiced in other Chinese speaking community in the world, e.g., USA, UK, Taiwan China, Malaysia, Japan, etc.

\subsection{Clinical research (Figure 2)}

We have been actively conducting researches and publishing papers in autism. The author had been the pioneer researcher of studying acupuncture as an adjunct for early intervention of autism since 1998. Researches conducted by the author concerning autism can be classified as follows:

A. Possible causes [32-34]

B. Other syndromes presenting with autistic phenotype [35-42]

C. Genetics [43-45]

D. Neuro-imaging [46-48]

E. Services [1]

F. Epidemiology [49]

G. Complementary \& alternative medicine: randomized control trials on acupuncture [50-57]

H. Early intervention [58]

I. Co-morbidities: epilepsy $[59,60]$

J. Others

(i) Validation of Chinese version of 3Di (collaboration with The Chinese University of Hong Kong)

(ii) Translation of ADOS to Chinese (Wong V, in preparation)

(iii) Dysmorphology, minor physical anomalies in children with ASD [61,62]

$\mathrm{K}$. Abstracts presented in international conferences [63-73]

\subsection{Symposium on autism (Figure 3)}

A satellite symposium on autism was held in September 18, 2002 in Hong Kong for the 9th International Child Neurology Congress (ICNC) and 7th Asian Oceanian Congress of Child Neurology (AOCCN) held in Beijing. Regular workshops on autism are also organized by our center. We had also organized the 1st World Autism Awareness Day in 


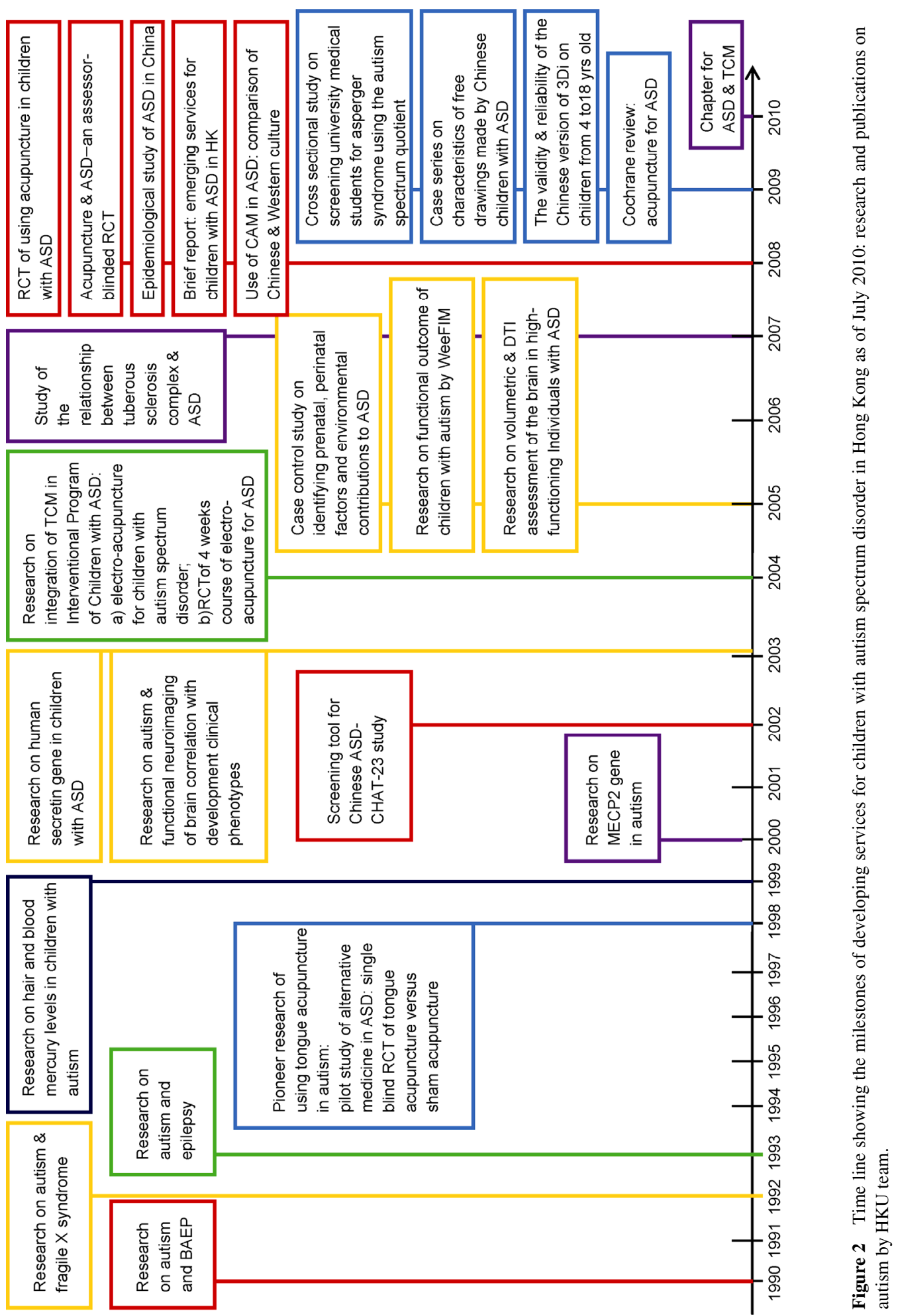




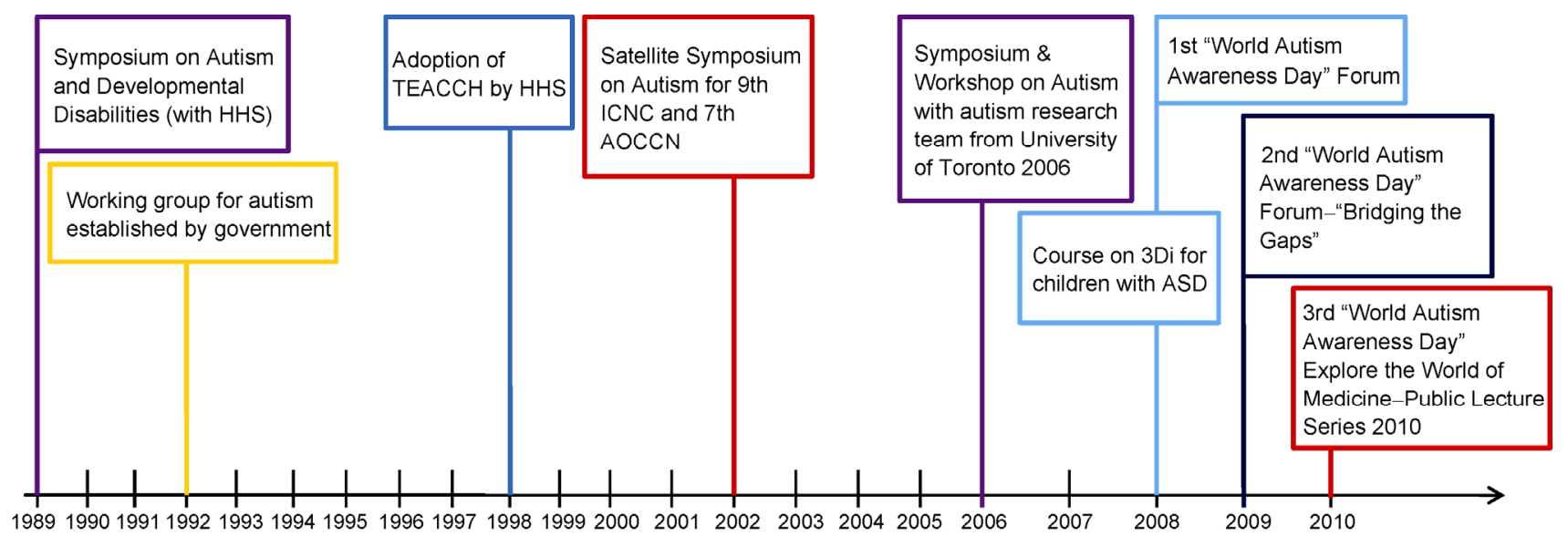

Figure 3 Time line showing the milestones of developing services for children with autism spectrum disorder in Hong Kong as of July 2010: organizations of meetings and symposium on autism by HKU team.

April 2, 2008 after the agreement signed by Autism Speaks in Qatar to designate April 2 as the Annual World Autism Awareness Day. We had also organized the 2nd World Autism Awareness Day in February 27, 2009 as the Vice President of Autism Speaks (Andy Shih) visiting Hong Kong. We had also organized training workshops for early intervention in 2006 with the Autism Research Unit of University of Toronto under Professor Wendy Roberts. We had organized a training workshop of use of 3Di with Professor David Skuse in 2008. We had collaborated with Autism Speaks since 2009 to start a project to increase awareness of autism in China. In 2010, a public lecture series was organized by the University of Hong Kong (HKU) and the author had self initiated the theme to be on autism in order to raise public awareness on the diagnosis and treatment of ASD.

(i) Symposium on Autism 2006 \& Post Symposium Workshops, Hong Kong, January 14-19, 2006

(ii) Certificate Course on Intervention for Children with Autism Spectrum Disorder 2006, Hong Kong, July 15-20 \& July 22-27, 2006

(iii) 1st "World Autism Awareness Day" Forum, Hong Kong, April 2, 2008 (http://www.autism123.hk/new.htm)

(iv) 2nd "World Autism Awareness Day" Forum "Bridging the Gaps", Hong Kong, February 27, 2009 (http://paed.hku.hk/services/autism/)

(v) 3rd "World Autism Awareness Day"-Explore the World of Medicine: Public Lecture Series 2010, HKU, Hong Kong, September 11, 2010 (http://www.hku.hk/ facmed/publiclecture2010b/)

There had been difficulties in rallying research funding for researches on community support for the current fragmented business model like services for autism in HK. There had been lack of support from the University of Hong Kong for clinical researches in autism. Over the years, the author had attempted to raise donations for increasing awareness of autism for Hong Kong. We had been supported by the Society for the Relief of Disabled Children for the 1st and 2nd WAAD with around USD 30000 per meeting. The author had repeatedly applied for central government funding to the Chief Executive (CE) Funding since 2007 for integration of services for autism in Hong Kong and also Jockey Club Charizty Foundation (2009). However, these proposals were never supported. The support for acupuncture research had been funded by Tung Wah Groups of Hospitals in 2002-2005.

Despite difficulties encountered by parents of autistic children, we as medical professionals had been encountering immense challenges with lack of resources and funding to support the comprehensive diagnostic and management issues of an autistic child from early childhood to transition of care to adulthood. However, this is not the problem in Hong Kong only as worldwide, especially in developing countries, similar challenges occurred. With increasing awareness and researches into autism we hope to close the gaps step by step.

The second part of this paper provides a summary report for the Autism Research Program under the University of Hong Kong and DKCAC.

\section{Analysis of the Autism Research Program in the University of Hong Kong (1985-2010 June) $(N=1441)$}

We had pioneered a unique model for autism in Hong Kong since 1985 for clinical service under the Hospital Authority within the Duchess of Kent Child Assessment Center and research based within the University of Hong Kong. We report the clinical profile of autism spectrum disorder in our Autism Research Program diagnosed in 1985-2010 June $(N=1441)$ (Figure 4). 


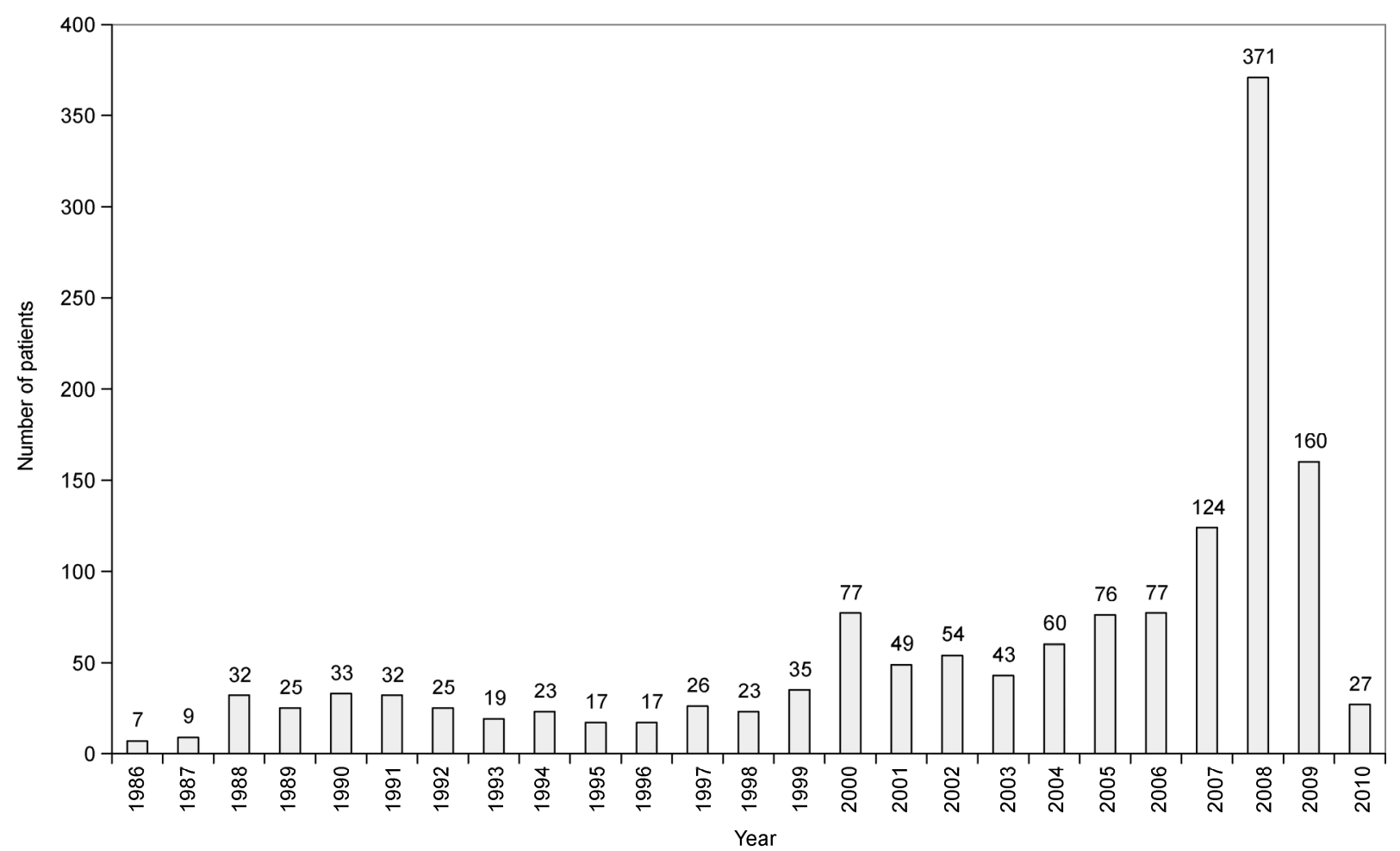

Figure 4 Number of cases diagnosed as autism by year (based on final follow-up).

\subsection{Subjects and methodology}

We had collected our patient profile in a computerized access format. This is based on a centralized autism database collected in the Duchess of Kent Child Assessment Center Child Assessment Centre (DKCAC) of the Duchess of Kent Children's Hospital (DKCH) from 1985 to 2010_a university based tripartite program for child neurology, developmental pediatrics \& neurohabilitation in Hong Kong. The autism database consisted of 1588 patients as of June 10, 2010 , comprising medical information by neuro-developmental pediatricians, assessment reports by multidiscipline. We had a standardized format for the interview and assessment.

\subsection{Latest diagnosis at last follow-up after initial medical assessment and subsequent team assessment (Figure 5)}

We based this report on those with final diagnosis of ASD made after initial medical assessment and final team assessment with clinical psychologist, speech therapist and occupational therapist at the latest follow up.

A summary of the latest diagnosis based on subsequent and the most current follow up sessions reported that of our 1588 patients, there are 466 with autism spectrum disorder, 605 with autistic disorder, 25 with PDD-NOS, 37 with high functioning autism, 66 with Asperger syndrome, 8 with Rett syndrome, 27 with global developmental delay, 16 with developmental language delay, 18 with other diagnosis (including ADHD, behavioral problem, bilateral hearing loss, disarticulation, fragile X, learning difficulties or SLI), 176 with specific autistic features or suspected autistic features, 66 with suspected autism spectrum disorder, 64 cases were found not to be autistic and 14 with unknown diagnosis.

In this report, 1441 patients with autism spectrum disorder/autistic disorder, PDD-NOS/high functioning autism/Asperger syndrome/autistic features or suspected autistic features or suspected autism spectrum disorder were analyzed.

\subsection{Demographic data}

Of the 1441 patients, $1262(87.6 \%)$ were males and 179 (12.4\%) were females. The male to female ratio=7:1.

Place of birth: This included 1252 born in Hong Kong, 164 born at other places, and 25 with unknown birth place.

Ethnicity: 1301 were Chinese, 52 were Asians (including Filipino, Indonesian, Indian, Thai, Japanese, Nepalese, Pakistani, etc.), 58 were non-Asian (British, Canadian, American, European, etc.) and 30 were of unknown ethnicity.

Gestational age: 1301 were born at full term (gestational week<37-40), and 58 patients with unknown birth terms.

For modes of delivery during birth, 723 patients were born by normal spontaneous delivery, 107 patients were born by vacuum extraction, 35 patients were born by low forceps, and 76 patients with records unknown.

Birth weight: 1344 with data available had a mean of 


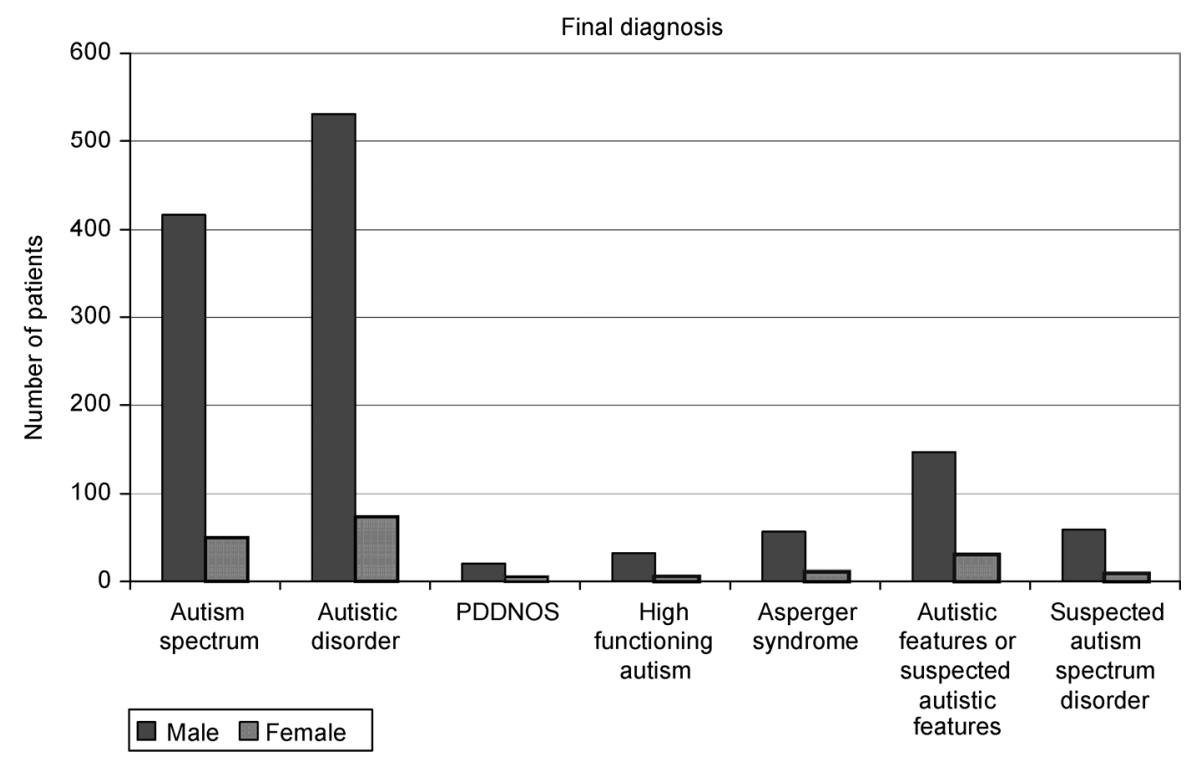

Figure 5 Final diagnosis at latest follow up for those assessed for autism spectrum disorder.

$3.14 \mathrm{~kg}$, median of $3.18 \mathrm{~kg}$, ranging between $0.74 \mathrm{~kg}$ to 8.3 $\mathrm{kg}$.

Prenatal history: 1074 had normal prenatal history, 59 mothers had threatened abortion, one had toxemia, 16 were of prematurity, three had medical illness and 243 mothers had other non-specified complications.

Perinatal history: 807 were normal, 484 had mild neonatal jaundice (with or without Phototherapy), three with neonatal jaundice with exchange transfusion, two with neonatal convulsion, six had intraventricular haemorrhage, one had septicemia, 11 had respiratory distress syndrome and 139 had other non-specified perinatal problems.

\subsection{Family history}

Sibling information: For patients having 0 older siblings, there were 1099 boy younger sibling and 1047 younger girl sibling. For those with one older sibling (of which 237 had boy sibling and 254 girl had sibling), with two older siblings ( 26 had boy sibling, 47 had girl sibling) and with three older siblings (all 10 had girl siblings).

In terms of the main caretaker of our patients, 763 had their mother, 303 had their grandparents, 498 had domestic helper and 62 with others as their primary caretaker.

Medical history in family: $97(7 \%)$ reported family history of autism spectrum disorder, 29 (2\%) with epilepsy, $298(21 \%)$ with language delay, $77(5 \%)$ with mental retardation and $76(5 \%)$ reported having a family history of psychiatric illnesses.

\subsection{Presenting symptoms}

The referral agencies for our patients consisted of 162 from Queen Mary Hospital, 575 from Maternal and Child Health
Center, 290 from General Practitioner, 397 from others and 17 unknown referrals.

The reason of referral (checklist interview) consisted of 815 cases of speech delay, 52 with poor eye contact, 221 with developmental delay, 47 with behavioral problem, 4 with school/learning problem, 4 with hearing problem, none with visual problem, 4 of motor problem, 32 of poor social skill problem, 28 of poor attention, 212 with other reasons and 22 with unknown reasons for referral.

Age of first symptom: Of the 729 patients with record of age of first symptom, the mean age was at 21 months, median at 20 months and range between 0 and 144 months.

Age at initial diagnosis: Of the 1378 patients recorded for age at initial diagnosis, the mean age was 35 months, median at 31 months and range between 0-158 months.

Age at autism diagnosis by referral agencies: Of the 1354 patients recorded for age at autistic diagnosis, the mean age was 43 months, median at 35 months and range between 10 and 408 months.

The initial diagnosis consisted of 363 patients as autism spectrum disorder, 337 as azutistic disorder, 53 patients as PDD-NOS, 22 as Asperger syndrome, 0 as childhood disintegrative disorder, 0 as Rett syndrome, 192 with global developmental delay, 63 with developmental language delay, 34 as others I (ADHD, behavioral problem, social problem, MR or developmental delay), 257 as others (autistic features or suspected autistic features or suspected Asperger), 96 as suspected autism spectrum disorder and 24 with unknown initial diagnosis.

There were 1139 patients diagnosed by developmental pediatricians, 111 by child neurologist, 45 by child psychiatrist, 104 by clinical psychologist, six by others and 36 diagnosed by unknown professionals. 


\subsection{Physical examination \& medical diseases dysmor- phology}

Dysmorphic features ( $N=156$ or $11 \%)$. Upon initial assessment and consecutive consultations, physical examinations were carried out on features including head, face, hands, feet, body proportions, relative size, position, proportions and shape of each body parts including the cranium, face, eyes, nose, mouth, ears, thorax, back, genitalia, limbs, skin, hair and teeth. Recordings of any abnormalities were done upon observation. Subjects were defined as dysmorphic if physical abnormalities, measurements abnormalities, descriptive features and malformations were observed. Within our database, there were 156 patients (11\%) with dysmorphic features.

Epilepsy ( $n=127) .127$ patients had epilepsy (8.8\%). These were 12 with simple partial seizure, 31 with complex partial seizure, 13 with partial seizure evolving to secondary generalization, 13 with absence seizure, 19 with myoclonic seizure, 20 with tonic seizure, three with clonic seizure, 56 with tonic-clonic seizure, four with atonic seizure, three with unclassified Seizure, seven with infantile spasm/West syndrome and 12 with status epilepticus.

Febrile seizure $(n=60)$. There were 60 cases of febrile convulsion (Table 2).

Other neurological diseases: 35 had ADHD, one had OCD, four had cerebral palsy, 509 had mental retardation or intellectual disability, seven with tuberous sclerosis, one with Rett syndrome, 12 with Dravet syndrome, two with fragile X syndrome and 19 with other neurological diseases.

\subsection{Assessment}

The assessment used for diagnosis included 280 cases using ADI-R (Autism Diagnostic Interview-Revised) [28], with a mean age at 78.96 months, median at 63 months and range between 22 and 317 months of age. The diagnosis with ADI-R showed 221 cases as autism and 59 cases being not autistic.

There were 312 cases using ADOS (Autism Diagnostic Observation Schedule) [29] as form of assessment, of which 89 cases were ASD, 210 cases as autism and 13 cases being not ASD.

There were 759 cases using CARS (Childhood Autism Rating Scale) [27] as assessment, with mean age at 43.87 months, median at 34 months and range between 13 and 234 months of age. The total score for CARS had a mean of

Table 2 Summary of febrile seizure $(n=60)$

\begin{tabular}{ccc}
\hline Febrile convulsion & $\begin{array}{c}\text { Age of onset of first seizure } \\
\text { (months) }\end{array}$ & No. of times \\
\hline Mean & 39 & 6 \\
Median & 15 & 2 \\
Range & $0-214$ & $1-88$ \\
\hline
\end{tabular}

34.85 , median at 34.5 and range between 17 and 52.5.

Of 1441 patients, intelligence quotient was performed by the clinical psychologists for 791 (54.9\%) patients: 181 (22.9\%) with normal IQ (IQ>85), 109 (13.9\%) have limited intelligence (IQ=71-84), 239 (30.3\%) had mild MR $(\mathrm{IQ}=51-70), 212(26.8 \%)$ had moderate MR (IQ=25-50) and $50(6 \%)$ with severe MR (IQ<25).

\subsection{Investigation}

Blood lead or mercury: Of the 62 patients tested for blood lead, four showed abnormal results. Of the 57 patients tested for blood mercury, 10 showed abnormal results. Of the 11 patients tested for hair mercury, eight showed abnormal results.

Urine for metabolic screening: Of the 315 patients performing urine for metabolic screening, 78 showed abnormal results. There were five with positive test results for interference ferric chloride, seven positive for interference ninhydrin, five with positive nitrosonaphthol and 61 with positive Benedict Test.

Thyroid function tests: Of the 130 patients tested for T4 TSH, five (3.8\%) had abnormal results. Of the five patients, four $(80 \%)$ patients had high TSH and one (10\%) with low TSH.

Chromosome study: Of the 326 patients tested for chromosome study, 28 had abnormal results (Table 3).

EEG: Of the 212 patients with EEG, 142 showed abnormal results (Table 4).

CT brain: Of the 98 patients with CT, 25 showed abnormal results (Table 5).

PET scan of brain: Of the 45 patients with PET scan performed on a research basis before and after acupuncture, $27(60 \%)$ had abnormal results pre-acupuncture (Table 6).

Table 3 Abnormal results for chromosomal study ( $n=28)$

\begin{tabular}{lcc}
\hline $\begin{array}{c}\text { Type of chromosome study } \\
(n=28)\end{array}$ & $\begin{array}{c}\text { Number with abnormal } \\
\text { results }\end{array}$ & $\begin{array}{c}\text { Percentage } \\
(\%)\end{array}$ \\
\hline \multicolumn{1}{c}{ Karotype } & $\begin{array}{c}14 \\
\text { (with 6 normal variants) }\end{array}$ & 50 \\
Molecular test & 1 & \\
• Normal variant & 2 & \\
- Fragile X syndrome & 1 & \\
- Rett syndrome & 1 & 35.8 \\
- SCN1A mutation & 1 & \\
- Silver Russell syndrome & & \\
- Other mutation (i.e., dele- & 4 & \\
$\quad$ tion/inversion/missense/trans & & \\
$\quad$ ition) & 2 & 7.1 \\
Sub-telomeric study & & \\
Molecular/clinical test & 1 & \\
• Soto syndrome & 1 & \\
• Kabuki syndrome & 28 & \\
Total & & \\
\hline
\end{tabular}


Table 4 Abnormal results in EEG ( $n=142)$

\begin{tabular}{ccc}
\hline $\begin{array}{c}\text { Type of abnormality in EEG } \\
(n=142)\end{array}$ & $\begin{array}{c}\text { Number of } \\
\text { patients }\end{array}$ & $\begin{array}{c}\text { Percentage } \\
(\%)\end{array}$ \\
\hline Slow background activity & 45 & 31.7 \\
Generalized spike wave abnormality & 13 & 9.1 \\
Focal spike waves & 17 & 12 \\
Hypsarrhythmia & 1 & 0.7 \\
Non-specific abnormalities & 66 & 46.5 \\
Total & 142 & 100 \\
\hline
\end{tabular}

Table 5 Abnormal results in CT scan of brain $(n=25)$

\begin{tabular}{ccc}
\hline $\begin{array}{c}\text { Type of abnormality in CT scan } \\
(n=25)\end{array}$ & $\begin{array}{c}\text { Number of } \\
\text { patients }\end{array}$ & $\begin{array}{c}\text { Percentage } \\
(\%)\end{array}$ \\
\hline Hydrocephalus & 6 & 24 \\
Atrophy & 5 & 20 \\
Calcification & 5 & 20 \\
Cyst & 3 & 12 \\
Tuberous sclerosis & 3 & 12 \\
Subdural haematoma & 1 & 4 \\
Chronic leukomalacia & 1 & 4 \\
Others - suspected leucodystrophy & 1 & 4 \\
Total & 25 & 100 \\
\hline
\end{tabular}

\subsection{Socio-economic status of parents}

Of 1441 patients, we record the occupation for 1359 fathers and 1364 mothers, the type of occupations is shown in Table 7. Education backgrounds are also recorded for 513 fathers and 431 mothers (Table 8).

Preschool education: 158 patients attended normal kindergarten, 107 attended early educational training centers (EETC), 84 attended integrated program in child care centre (ICCC) and 207 attended special child care centre (SCCC) as preschools.

Primary and secondary school education: There are 213 patients attending normal primary school, 31 attended normal secondary school, 321 attended special schools and one patient attended university. There were also 15 patients with employment/vocational training.

Mortality: There are three deaths recorded within our database, the cause of death included one case of Rett syndrome with sudden death, one case died of subsequent acute lymphoblastic leukemia and one case of epilepsy and died of related complications.
Table 6 Abnormal results in PET scan of the brain $(n=27)$

\begin{tabular}{ccc}
\hline $\begin{array}{c}\text { Type of abnormality in PET scan } \\
(n=27)\end{array}$ & $\begin{array}{c}\text { Number of } \\
\text { patients }\end{array}$ & $\begin{array}{c}\text { Percentage } \\
(\%)\end{array}$ \\
\hline Hypo-metabolism in cerebrum & 15 & 55.6 \\
Hypo-metabolism in frontal cortex & 6 & 22.2 \\
Hypo-metabolism in brainstem & 3 & 11.1 \\
Hypo-metabolism in parietal lobe & 1 & 3.7 \\
Hypo-metabolism in temporal lobe & 1 & 3.7 \\
Hyper-metabolism in multiple areas of cere- & 1 & 3.7 \\
brum & 27 & 100 \\
Total & &
\end{tabular}

Table 7 Occupation of parents

\begin{tabular}{ccccc}
\hline Occupation & Father & $\begin{array}{c}\text { Percentage } \\
(\%)\end{array}$ & Mother & $\begin{array}{c}\text { Percentage } \\
(\%)\end{array}$ \\
\hline Professional & 294 & 21.6 & 176 & 12.9 \\
Managerial and technical & 456 & 33.6 & 170 & 12.5 \\
Clerical and minor supervi- & 392 & 28.9 & 268 & 19.6 \\
sory and skilled manual & 147 & 10.8 & 51 & 3.7 \\
Semi-skilled manual & 48 & 3.5 & 12 & 0.9 \\
Unskilled manual & 17 & 1.3 & 685 & 50.2 \\
Unemployment/Housewife & 5 & 0.3 & 2 & 0.2 \\
Retired & 1359 & 100 & 1364 & 100 \\
Total & & & &
\end{tabular}

\section{Background information of developmental pediatrics under the community pediatrics pro- gram of the Hong Kong College of Pediatricians for basic pediatrics trainees}

DKCAC is one of seven child assessment centers in Hong Kong. Clinical service has been provided since July 1985 and it was officially opened in 1987. It is the only one child assessment center situated on Hong Kong Island in Hong Kong. For historical reason, it is the only one that is governed under the Hospital Authority as it has been a university affiliated CAC program all along. All the other six child assessment centers are run by child assessment service of Department of Health, Hong Kong [74].

DKCAC provides comprehensive specialized assessment services for children with developmental problems for children mainly reside on Hong Kong Island and off-shore islands. There are also private referrals from Macau and other parts of mainland China. The multi-disciplinary team for child assessment at DKCAC is similar to other CAC under CAS (DH) but the actual manpower provision may be dif-

Table 8 Education of parents

\begin{tabular}{|c|c|c|c|c|}
\hline Education & Father & Percentage $(\%)$ & Mother & Percentage $(\%)$ \\
\hline No schooling/kindergarten & $3(0.6 \%)$ & 0.6 & $10(2.3 \%)$ & 2.3 \\
\hline Primary & $69(13.4 \%)$ & 13.4 & $78(18.1 \%)$ & 18.1 \\
\hline Secondary & $147(28.7 \%)$ & 28.7 & $150(34.8 \%)$ & 34.8 \\
\hline Total & 513 & 100 & 431 & 100 \\
\hline
\end{tabular}


ferent and it may account for some of the difference in the service provided, e.g., waiting time of patients. The staff provision at DKCAC is listed in Table 9.

In terms of child assessment activities, DKCAC is similar to any one of the child assessment center under CAS, DH. As for 2009, there were 6560 attendances to DKCAC including referral to pediatricians and various allied health professionals (clinical psychologists $\mathrm{CP}$, speech therapist ST, occupational therapist OT, physiotherapist PT, audiologist and optometrist) for new assessment, interim supportive or rehabilitation services or follow up (Table 10).

Among them, there were 531 new cases with various developmental problems assessed by pediatricians (Table 11), 109 new cases with articulation problem assessed by speech therapist in groups and 36 new cases assessed by audiologist that failed neonatal hearing screening or with suspected hearing loss.

There are 676 new cases of various developmental problems assessed in 2009. Among the 531 referrals for developmental assessment, $68 \%$ aged from 0 to 3 years, $18.5 \%$ aged from 4 to 5 years, and the rest aged $\geqslant 6$ years (Table 11). Majority (41.2\%) of these referrals were from Mater- nity and Child Health Centers of the Department of Health, $34 \%$ from specialty clinics at the Hospital Authority hospitals (Queen Mary Hospital, the Grantham Hospital and Pamela Youde Nethersole Eastern Hospital, Orthopaedics Department at $\mathrm{DKCH}$ ), 20.9\% from private doctors and the rest from other sources (e.g., school educational psychologists, private clinical psychologists) (Table 12).

Major developmental problems identified in all new cases (i.e., including 531 for developmental assessment, 109 for articulation problem and 36 for suspected hearing problem) included developmental delay, language and speech disorders, autism or autistic spectrum disorder and attention deficit hyperactivity disorder (Table 13). ASD ranked 4th commonest developmental problems identified. It should be noted that the referral diagnoses may not necessarily be the diagnosis of assessment and is not included.

Children identified to have developmental problems are referred for training depending on severity of their problems. For mild cases, children may be referred to various disciplines including PT, OT, ST for short-term training and clinical follow up to review the progress. Community resources may also be introduced. For moderate to severe

Table 9 Staff providing service at $\mathrm{DKCAC}^{\text {a) }}$

\begin{tabular}{cc}
\hline Medical team & Number \\
\hline Professor in developmental pediatrics, child neurology and neuro-rehabilitation & $1^{*}$ \\
Consultant & $1^{*}$ \\
Associate consultant & $3^{*}$ \\
Allied health professionals & 1 full time, 2 part-time \\
Clinical psychologist (CP) & 1 part-time senior OT, 2 OT I \\
Occupational therapist (OT) & 1 full time PTI, 1 full time PT II \\
Physiotherapist (PT) & 1 full time, 2 part time ST \\
Speech therapist (ST) & 2 full time \\
Medical social worker m (MSW) & 1 full time \\
Audiologist & 1 full time \\
Optometrist & 1 full time senior nurse, 4 full time registered nurses \\
Nursing staff & 1 part time (depending on availability of research funding) \\
\hline
\end{tabular}

a) *, Tripartite model of child neurology/developmental pediatrics/neurohabilitation to provide acute care for in and out-patient services for neurological diseases and rehabilitation service in the Hong Kong West Cluster which also included another teaching hospital, i.e., Queen Mary Hospital. NB, developmental milestones for manpower resources in this HKU-HA (DKCAC) model: 1, CAC was established in 1985 with only 1 team (SMO, MO, CP, ST, PT,OT, MSW, Audiologist, Optometrist, 1 nurse). 2, Children Habilitation Institute (CHI) was established in 1998 with extra manpower for rehabilitation (SMO being upgraded to 1 consultant, MO, CP, ST, PT,OT, MSW, 1 ward manager, I nurse specialist, 2 nurses). 3, With the resignation of the consultant in 2007, the funding could cover upgrading of 1 SMO to consultant and 3 fellows to associate consultants. The University of Hong Kong was given the role to pilot start this CAC program in DKCH in 1982 by Prof. C Y Yeung (Head) and Dr. W Y Lui (Head of Child Neurology), and V Wong (first author) who was lecturer since 1980 was given this task of pioneer organization of this DKCAC model in 1985 after training in UK in 1985, and she was later promoted to senior lecturer in 1991 and professor in 1996.

Table 10 First attendances of all cases referred to DKCAC from 1st January to 31st December 2009

\begin{tabular}{|c|c|c|c|c|c|c|c|c|c|c|c|c|c|c|c|c|c|c|}
\hline \multirow[t]{2}{*}{$\begin{array}{c}\text { No. of } \\
\text { attendance }\end{array}$} & \multicolumn{2}{|c|}{ Medical doctor } & \multicolumn{2}{|c|}{$\begin{array}{c}\text { Clinical } \\
\text { psychologist }\end{array}$} & \multicolumn{2}{|c|}{$\begin{array}{c}\text { Speech } \\
\text { therapist }\end{array}$} & \multicolumn{2}{|c|}{$\begin{array}{l}\text { Physio- } \\
\text { therapist }\end{array}$} & \multicolumn{2}{|c|}{$\begin{array}{c}\text { Occupational } \\
\text { therapist }\end{array}$} & \multicolumn{2}{|c|}{$\begin{array}{c}\text { Medical social } \\
\text { worker }\end{array}$} & \multicolumn{2}{|c|}{ Audiologist } & \multicolumn{2}{|c|}{ Optometrist } & \multicolumn{2}{|c|}{ Dietitian } \\
\hline & $\mathrm{N} / \mathrm{P}$ & $\mathrm{R} / \mathrm{A}$ & $\mathrm{N} / \mathrm{P}$ & $\mathrm{R} / \mathrm{A}$ & $\mathrm{N} / \mathrm{P}$ & $\mathrm{R} / \mathrm{A}$ & $\mathrm{N} / \mathrm{P}$ & $\mathrm{R} / \mathrm{A}$ & $\mathrm{N} / \mathrm{P}$ & $\mathrm{R} / \mathrm{A}$ & $\mathrm{N} / \mathrm{P}$ & $\mathrm{R} / \mathrm{A}$ & $\mathrm{N} / \mathrm{P}$ & $\mathrm{R} / \mathrm{A}$ & $\mathrm{N} / \mathrm{P}$ & $\mathrm{R} / \mathrm{A}$ & $\mathrm{N} / \mathrm{P}$ & $\mathrm{R} / \mathrm{A}$ \\
\hline \multirow[t]{2}{*}{6560} & 712 & 2938 & 490 & 1267 & 435 & 1559 & 271 & 1623 & 329 & 1606 & 1936 & 1371 & 708 & 378 & 555 & 663 & 124 & 18 \\
\hline & (85) & (163) & (10) & (8) & (7) & (5) & (18) & (81) & (12) & (16) & (15) & (0) & (9) & $(0)$ & $(7)$ & (6) & $(0)$ & (0) \\
\hline
\end{tabular}

a) N/P, new patient; ( ), private patient; R/A, reassessment/follow-up. 
Table 11 First attendances of all cases by referral source, from 1st January to 31 st December $2009^{\text {a) }}$

\begin{tabular}{|c|c|c|c|c|c|c|c|}
\hline & (A) & (B) & (C) & (D) & (E) & (F) & Total \\
\hline Development assessment clinic & 136 & 7 & 0 & 78 & 75 & 10 & 306 \\
\hline Speech delay clinic & 67 & 0 & 1 & 20 & 19 & 0 & 107 \\
\hline Very low birth weight clinic & 0 & 1 & 0 & 77 & 0 & 0 & 78 \\
\hline Neuro behavioral clinic & 16 & 0 & 0 & 6 & 17 & 1 & 40 \\
\hline Total & $219(41.24 \%)$ & $8(1.51 \%)$ & $1(0.19 \%)$ & $181(34.09 \%)$ & $111(20.9 \%)$ & $11(2.07 \%)$ & $531(100 \%)$ \\
\hline
\end{tabular}

a) (A) General outpatient department under Hospital Authority or maternal and child health center under Department of Health; (B) Specialty outpatient clinic from different specialty of own hospital/clinic (including Queen Mary Hospital and Duchess of Kent Children Hospital); (C) In-patient discharged from different specialty of own hospital (including Queen Mary Hospital and Duchess of Kent Children Hospital); (D) Specialty outpatient clinic from other HA hospitals; (E) General/private practitioner; (F) Others.

Table 12 First attendances of all cases by age, from 1st January to 31 st December $2009^{\text {a) }}$

\begin{tabular}{|c|c|c|c|c|c|c|c|c|c|c|c|c|c|c|c|c|}
\hline Age & 1 & 2 & 3 & 4 & 5 & 6 & 7 & 8 & 9 & 10 & 11 & 12 & 13 & 14 & $>14$ & Total \\
\hline $\begin{array}{l}\text { Neuro-development as- } \\
\text { sessment clinic }\end{array}$ & 51 & 93 & 48 & 32 & 32 & 15 & 14 & 11 & 7 & 1 & 1 & 1 & 0 & 0 & 0 & 306 \\
\hline Speech delay clinic & 0 & 23 & 63 & 19 & 2 & 0 & 0 & 0 & 0 & 0 & 0 & 0 & 0 & 0 & 0 & 107 \\
\hline $\begin{array}{c}\text { Very low birth weight } \\
\text { clinic }^{+}\end{array}$ & 78 & 0 & 0 & 0 & 0 & 0 & 0 & 0 & 0 & 0 & 0 & 0 & 0 & 0 & 0 & 78 \\
\hline Neuro-behavioral clinic & 0 & 1 & 5 & 7 & 6 & 8 & 3 & 1 & 5 & 0 & 1 & 2 & 0 & 1 & 0 & 40 \\
\hline Total & 129 & 117 & 116 & 58 & 40 & 23 & 17 & 12 & 12 & 1 & 2 & 3 & 0 & 1 & 0 & 531 \\
\hline
\end{tabular}

a) + , Assessment performed at the corrected age 17-19 months.

Table 13 Major developmental problems of all cases diagnosed for new cases $(N=676)$, from 1 st January to 31 st December $2009^{\text {a) }}$

\begin{tabular}{|c|c|}
\hline Major developmental problems & Number $^{\#}$ \\
\hline Academic underachieve disorder (AUD) & 0 \\
\hline Attention deficit/hyperactivity disorder (ADHD) & 45 \\
\hline Autism/autistic spectrum disorder (ASD) & 81 \\
\hline Cerebral palsy (CP) & 4 \\
\hline Chromosomal/syndromal disorder & 0 \\
\hline Development delay (partial/global) & 220 \\
\hline Dysarticulation & 92 \\
\hline Hearing impairment (permanent+transient) & 42 \\
\hline Language and speech developmental disorder & 108 \\
\hline Mental retardation (MR) & 2 \\
\hline Normal & 94 \\
\hline Specific learning difficulties (SLD) & 16 \\
\hline Visual impairment (significant) & 8 \\
\hline
\end{tabular}

a) \#, Total number $>676$ as there might be more than one diagnosis for a single child.

cases, children will be referred to medical social worker for placement in training centers under Social Welfare Department for pre-school age children and for recommendations of additional education supportive service at local school under Education Department Bureau (EDB) or to be placed at special schools under EDB for school aged children.

As DKCAC is operated under Hospital Authority, it also provides further neurological evaluation if deemed necessary and interim training service for the children until they receive appropriate training in the community. For children identified to have developmental problems at CAC under $\mathrm{CAS}, \mathrm{DH}$, they will be referred back to Department of Pediatrics under various HA hospitals for further neurological evaluation if deemed necessary and interim training service, e.g., PT, ST, OT at HA hospitals until they receive appropriate training in the community [74].

As there is operational difference between Department of Health and Hospital Authority, the care pathway for certain developmental problems may be varied between DKCAC and CAC under CAS, DH. For example, all cases with suspected or diagnosed ASD at CAS, DH will be referred to Child and Adolescent Psychiatric Service of HA hospitals for further evaluation and treatment [74]. In contrast, only children with significant behavioural problem with ASD or children considered to benefit from pre-school preparatory class will be referred to Department of Psychiatry at Queen Mary Hospital. 
3.1 Analysis of assessment service for children with ASD at DKCAC in 2009

\subsubsection{Methods}

All children assessed between January and December 2009 at Duchess of Kent Child Assessment Center with an assessment diagnosis of ASD (including AD, AS and PDD) were included for analysis.

\subsubsection{Results}

There were 98 cases diagnosed to have ASD after assessment in 2009. Among them, 89 cases were non-private and we report these 89 cases.

Time of referral to time of assessment: The age at the time of referral was 32.4 months (mean), 25.68 months (median) and range from 12.76 months to 134.86 months. The age at the time of assessment was 36.2 months (mean), 29.62 months (median) and range from 16.34 months to 140.19 months. The waiting time from referral to any assessment was 3.58 months (mean), 2.79 months (median) and range from 0 to 12.03 months.

The waiting time from referral to paediatrician assessment was 3.80 months (mean), 2.93 months (median) and range from 0.16 to 12.62 months (Table 14). It is noteworthy that the waiting time was shorter than the waiting time for child with other developmental problems. It is our CAC triage guideline that child with referral diagnosis of ASD or suspected ASD with adequate information provided in the referral letter will be triaged as priority 2 (waiting time around 8 weeks) and those otherwise will be triaged as routine (waiting time around 16 months) according to HA performance pledge. As 89 cases that were diagnosed to have ASD, only 58 were referred for suspected ASD/Asperger/ autism/PDD while the others were referred for other developmental problems like language delay, developmental de- lay, behavioural problems, social delay etc. This might partly account for the failure to meet the performance pledge in addition to the manpower problem.

Time of assessment to allied health assessment/training: Among 89 cases, 80 were referred to medical social worker MSW for placement at community training centres or related services. The waiting time was 0.97 month (mean), 0.53 months (median) and range from 0 to 10.85 months. For the nine cases that were not referred, three were assessed and referred for placement (one from other CAC under CAS, $\mathrm{DH}$ and two from private) before seen at DKCAC, one was attending special school and one attending private service, one planned to immigrate to USA and one defaulted follow up assessment. We were not able to provide the waiting time from assessment as there could be great variation among individuals depending on parental preference of training centers and places available in various centers. The roughly estimated waiting time is available from Social Welfare Department, Hong Kong [7].

Sixty cases were seen by clinical psychologist either on the same date of assessment by pediatrician or for further evaluation. The waiting time was 3.02 months (mean), 2.02 months (median) and range from 0 to 22.03 months. Based on our departmental protocol, very young child referred to $\mathrm{CP}$ will be evaluated when they reach 2.5 years. It is therefore important to note that most, if not all of these children had already been seen by paediatrician and referral for placement if necessary before confirmation of diagnosis by $\mathrm{CP}$. The waiting time to be further evaluated by clinical psychologist is not a factor that deters a child from receiving training but admittedly, this can be a potential cause of parental anxiety.

The waiting time for various allied health professionals is also outlined in Table 14.

Table 14 Time from referral to time of assessment for children diagnosed to have ASD, from 1st January to 31 st December 2009

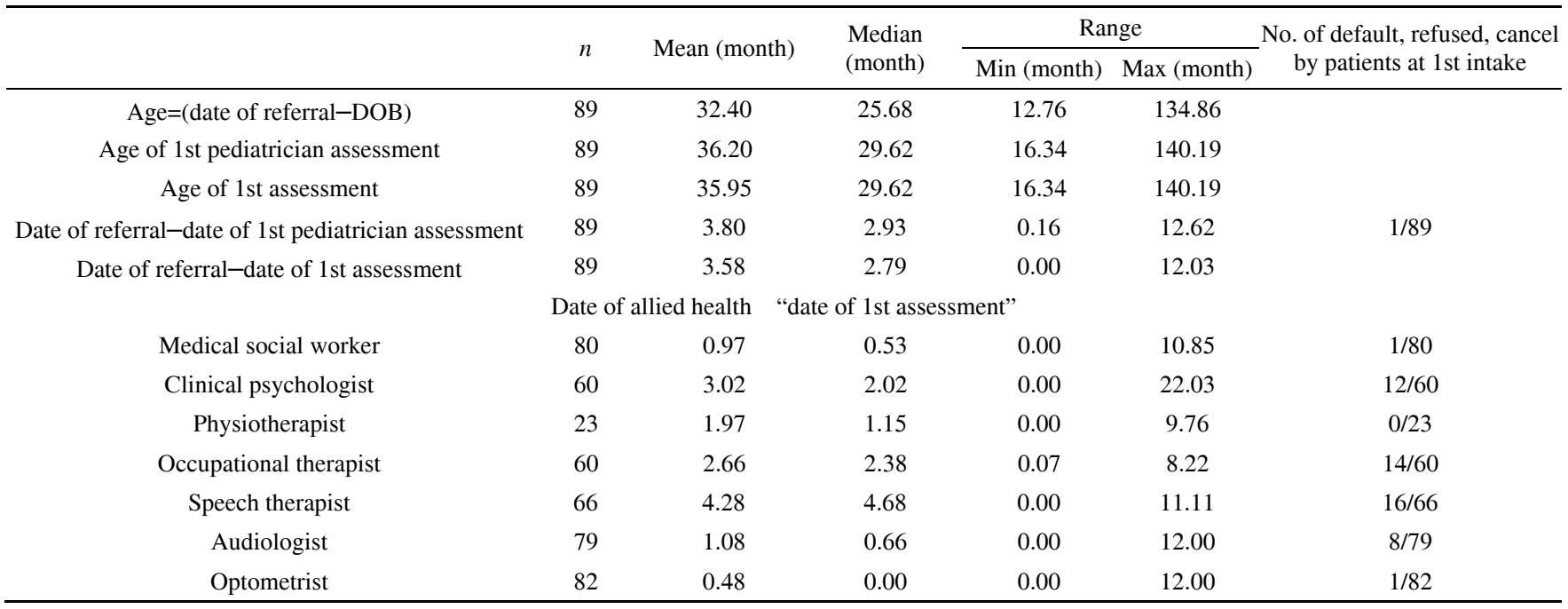




\subsection{Discussion}

The National Autism Plan for Children (NAS) in UK 2003 [75] suggested a three stage assessment framework for any child with a possible developmental problem including that of ASD. Stage 1 refers to a general multi-disciplinary developmental assessment, Stage 2 refers to a secondary level of multi-disciplinary, multi-agency assessment at which an individual educational plan/family care plan should be made and Stage 3 refers to a tertiary center for ASD assessment. The center will provide second opinion in case of diagnostic doubt and specific advice for treatment or key transitional stages. Access to pediatric neurology, metabolic medicine, neuropsychiatry and other specialist therapy should be available. The center should also provide a lead in local research, data organization and analysis. A suggested time frame for completion of assessment of Stage 1 and Stage 2 is 30 weeks. NAS reflected that while many local areas have a child development service, models vary considerably. In addition, Stage 1 and 2 may coincide.

For Hong Kong, the "Stage 1" service is partly provided by Maternity and Child Health Center (MCHC) at the public sector and private pediatricians. The assessment is a brief screening rather than a general multi-disciplinary assessment. Detailed assessment, i.e., Stage 2 is provided at child assessment centers and in 1 or 2 private centers.

We had been providing a one stop 3 stages approach in the first assessment setting as we are operating under the university led-Hospital Authority model. Unfortunately, there has always been manpower problem. The difficulty in meeting the expected standard for even a child with any developmental disorder was reported by an assessment center in UK. While our priority triage system for children with ASD might account for the shorter waiting time at our center when compared to the UK center, we need to admit that this could also affect the waiting time of children with other developmental disorders. More detailed evaluation is warranted to explore if there is any impact on the differential waiting time for assessment of children with various developmental problems so as to advise the government on resource allocation.

\subsection{Supportive service for children with ASD at DKCAC (Figure 6)}

The service available for ASD in Hong Kong has been fragmented and uncoordinated. The assessment service has been largely provided in the public sectors by the seven child assessment centers. Although recent studies have supported early diagnosis and interventions in improving the outcome of children with ASD, the service provision in terms of assessment and treatment is hindered by the limitation in resources. To complicate the picture, there have been more and more private services available. Some of these training methods do not have good level of scientific evidence, yet they have been widely accepted and at a high cost. This also leads to increasing demand from the parents for provision of similar training in the public sectors. There are essentially three important aspects of service provision including diagnosis, treatment, and well designed research for more accurate early diagnosis, evidenced based treatment and evaluation of cost effectiveness of training program so as to help establish care pathway for patients with ASD from early childhood to adulthood

There has been a good track record at DKCAC in providing clinical and research work on ASD under the leadership of HKU. The services provided for ASD is depicted in Table 14 and briefly outlined as follows:

(i) Continuing improvement in assessment service. In addition to the conventional use of Griffiths mental developmental scale, childhood autism rating scale, modified checklist for autism (CHAT-23) in toddlers for Chinese children [42] and Diagnostic and Statistical Manual of Mental Disorders DSM IV-TR [24], staff have been trained in recent few years in conducting new diagnostic tools including autism diagnostic interview-revised ADI-R [28], autism diagnostic observation scale ADOS [29] and the development, diagnostic and dimensional interview 3Di [76] facilitate early diagnosis and improve diagnostic accuracy.

(ii) Clinical evaluation and follow up. As a minority of cases with ASD may be associated with a medical condition or known syndrome (secondary ASD), neurological evaluation including genetic referral, selective metabolic testing, EEG may be warranted. Unlike CAC under CAS, DH where the cases will be referred to Department of Pediatrics or child and adolescent psychiatric service at different HA hospitals, the clinical evaluation will be offered at DKCAC with backup support from Queen Mary Hospital. In addition, longer term clinical follow up may be offered to pre-school age children until they enter primary school or if they are suffered from secondary ASD.

(iii) Provision of interim training. As aforementioned, children diagnosed to have ASD will be referred to various disciplines for short term training and MSW for placement in specialized community training centres. As the waiting line for placement of training service is unduly long, DKCAC will provide an interim training service for some of the cases if deemed necessary. A specific interim multi-disciplinary training program is as follows:

(1) Three parenting workshops conducted by clinical psychologists to introduce ASD, social skills training, different training methods and local resources to parents

(2) Two individual training sessions delivered by trained nurses to parents and children with ASD to enhance eye contact, index pointing, use of gesture and simple speech (i.e., Autism 123 Program) [58]

(3) Five-session multi-discipline training group conduct- 


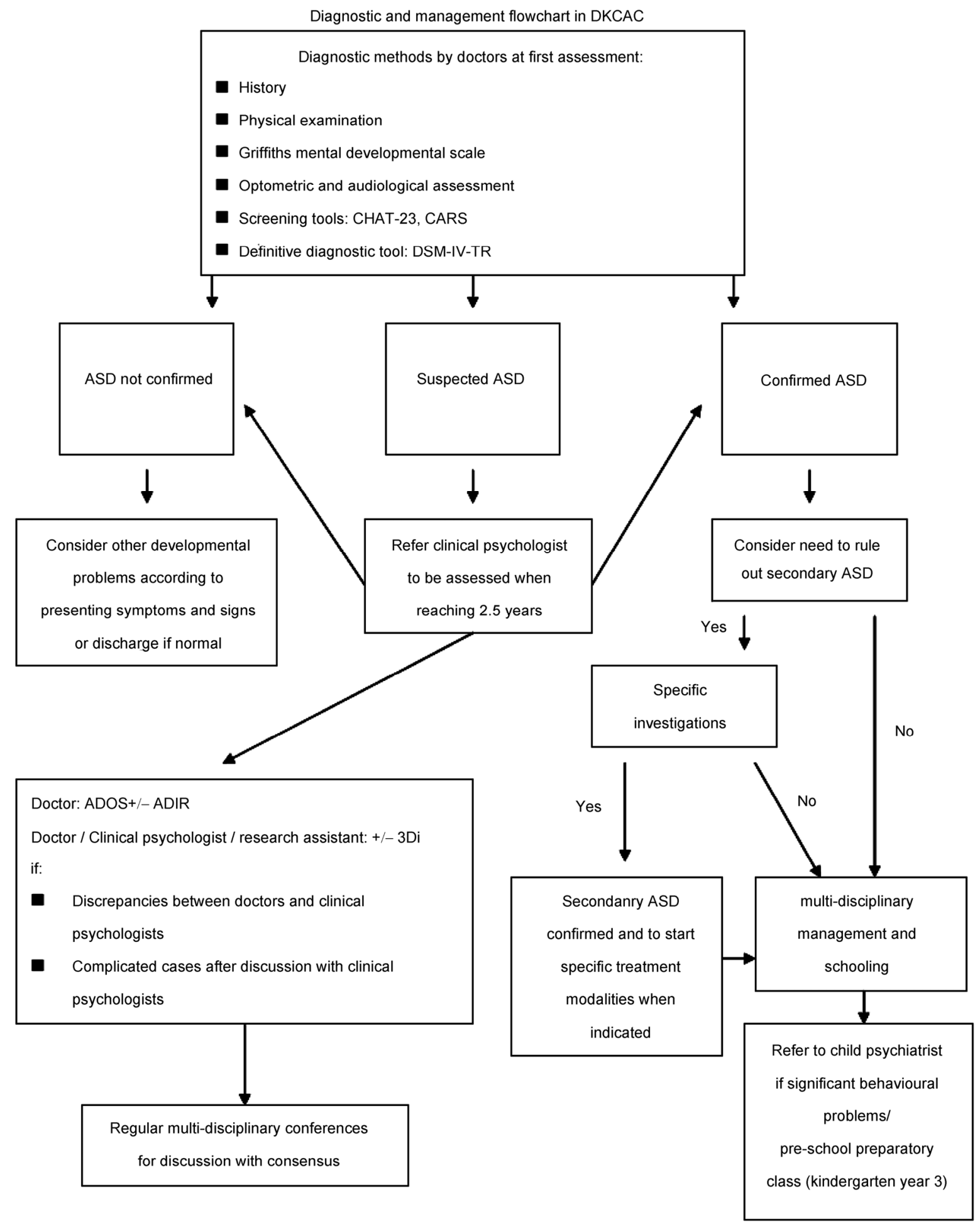

Figure 6 Guideline for developmental pediatrics training program — training children referred to our center for developmental problems with suspected autism.

ed by OT, ST and MSW to facilitate child's social communication skills and educate parental handling skills

Other interim training service include

(1) Sensorimotor skills training group, fine motor skill training group, sensory integrative training offered by OT
(2) Individual language training to children aged three years and above was offered by ST

(3)Individual or group training offered by $\mathrm{CP}$

(iv) Other supportive services:

(1) Increase public awareness 
a. Organized 1st World Autism Awareness Day on April 2nd, 2008 in Hong Kong

b. Organized 2nd World Autism Awareness Day on February 27th, 2009

(2) Provision of training to medical and paramedical professionals, community doctors and health workers to increase their awareness of ASD

a. DKCAC is accredited as one of the training centre for developmental pediatrics under the community pediatrics program of the Hong Kong College of Pediatricians for basic pediatrics trainee

b. CP and ST have been providing training for trainees of their respective sub-specialties

c. Provision of Module of Neurodevelopment \& Neuro-habilitation with ASD as the curriculum in the Postgraduate Diploma in Child Health organized by Department of Pediatrics and Adolescent Medicine, HKU (since 2003)

d. Organized training course for 3Di, a new diagnostic tool for ASD and other behavioral problem in children by collaboration with UK

\section{Abbreviation}

ADI-R = Autism Diagnostic Interview-Revised ADOS = Autism Diagnostic Observation Schedule AOCCN $=$ Asian \& Oceanian Congress of Child Neurology

BAEP $=$ Brainstem Auditory Evoked Potential

$\mathrm{CHAT}=$ Checklist for Autism in Toddlers

HHS $=$ Heep Hong Society

HKIE $=$ Hong Kong Institute of Education

$\mathrm{HKU}=$ The University of Hong Kong

ICNC $=$ International Child Neurology Congress

$\mathrm{MECP} 2=$ methyl $\mathrm{CpG}$ binding protein 2

TEACCH $=$ treatment and education of autistic and related communication-handicapped children

The authors would like to acknowledge all the past and current team members who contributed to the clinical services rendered for this Autism Program in Duchess of Kent Children Hospital (associate consultants $-D r$. Ada Yung and Dr. Sophelia Chan) under the Hospital Authority as well as to Mr. Vivian Lee, chairman of the Society for the Relief of Disabled Children (SRDC) for supporting symposiums to increase public awareness for autism (2008-2009) and Tung Wah Groups of Hospitals for supporting my pioneer research for integration of traditional Chinese medicine and western medicine for autism (2003-2006). I am also grateful to all the autistic children and their parents who had provided me with the impetus and momentum to stay with perseverance in this "lonely research land" for 30 years.

1 Wong VC, Hui SL. Brief report: emerging services for children with autism spectrum disorders in Hong Kong (1960-2004). J Autism Dev Disord, 2008, 38: 383-389
2 Central Registry of Rehabilitation (CRR). [2010-10-11]. http://www. hwfb.gov.hk

3 Special Assessment Centre, Special Health Service, Department of Health. [2011-01-14]. http://www.parentsassn.org.hk

4 Fu Hong Society, Hong Kong. [2011-01-14]. http://www.fuhong. org/hdc/

5 Duchess of Kent Children Hospital. [2010-10-11]. www.dhcas. gov.hk

6 Wong VC. Professor Virginia Wong Chun Nei. [2010-10-17]. http://www.professorvwong.hk

7 Social Welfare Department. [2010-10-11]. http://www.swd.gov.hk

8 Heep Hong Society. [2010-10-11]. http://www.heephong.org

9 The Spastics Association of Hong Kong. [2010-10-11]. http://www. sahk1963.org.hk

10 Caritas Rehabilitation Service, Caritas Hospital. [2011-01-14]. http://swsd.citac.edu.hk/

11 The Child and Adolescent Mental Health Community Support Project, Social Welfare Department, HA. [2011-01-14]. http://www.swd.gov. hk/en/index/site_pubsvc/page_medical/sub_camhcsp/

12 iCare - Voice and Speech Therapy Centre. [2011-01-14]. http://www. icare.com.hk/en/index.html

13 Autism Partnership Hong Kong. [2011-01-14]. http://www. autismpartnership.com.hk

14 iCan, Whole Person Development Institute. [2011-01-14]. http://www. ican.com.hk/index.php

15 New PAGE Learning \& Developmental Consultants. [2011-01-14]. http://www.newpage.hk

16 Project Aspire. [2010-10-11]. http://www.ied.edu.hk/aspire

17 The Society for the Welfare of the Autistic Persons. [2010-10-11]. http://www.swap.org.hk/

18 Autism HK. [2010-10-11]. http://www.autism.hk/

19 Hong Kong Autism Awareness Alliance. [2011-01-14]. http://www. autism-day.org/

20 The Parent Association of Autistic Children in Mainstream Ed, PAAC. [2011-01-14]. http://www.paacme.org.hk/paacme.html

21 The Parent's Association of Pre-School Handicapped Children. [2011-01-14]. http://www.parentsassn.org.hk

22 The Salvation Army's Family Support Service for Persons with Autism. [2011-01-14]. http://www.salvation.org.hk/ssd_web/fsspa/

23 Intellectually Disabled Education and Advocacy League (IDEAL). [2011-01-14]. http://www.ideal.org.hk

24 Griffiths R. The Abilities of Young Children. Revised ed. Buckinghamshire: The Text Agency, 1984

25 Lowe M, Costello AJ. Symbolic Play Test Manual. 2nd ed. Berkshire, England: NFER-Nelson, 1984

26 American Psychiatric Association. Diagnostic and Statistical Manual of Mental Disorders. 4th ed. Washington, DC, 1994

27 Schopler E, Reichler RJ, Renner BR. The Childhood Autism Rating Scale (CARS) for Diagnostic Screening and Classification in Autism. New York: Irvington, 1986

28 Lord C, Rutter M, Le Couteur A. Autism Diagnostic InterviewRevised: a revised version of a diagnostic interview for caregivers of individuals with possible pervasive developmental disorders. J Autism Dev Disord, 1994, 24: 659-685

29 Lord C, Rutter M, Goode S, Heemsbergen J, Jordan H, Mawhood L, Schopler E. Autism diagnostic observation schedule: a standardized observation of communicative and social behavior. J Autism Dev Disord, 1989, 19: 185-212

30 Baren-Cohen S, Wheelwright S, Cox A, Baird G, Charman T, Swettenham J, Drew A, Doehring P. Early identification of autism by the Checklist for Autism in Toddlers (CHAT). J Royal Soc Med, 2000, 93: 521-525

31 Robbins DL, Fein D, Barton ML, Green JA. The modified checklist of autism in toddlers: an initial study investigating the early detection of autism and pervasive developmental disorders. J Autism Dev Dis- 
ord, 2001, 31: 131-144

32 Wong V, Wong SN. Brainstem auditory evoked potential study in children with autistic disorder. J Autism Dev Disord, 1991, 21: 329-340

33 Ip P, Wong V, Ho M, Lee J, Wong W. Mercury exposure in children with autistic spectrum disorder: case-control study. J Child Neurol, 2004, 19: 431-434

34 Lau K. Acupuncture and autism spectrum disorder-an assessor-blinded randomized controlled trial. Dissertation for Master's Degree. Hong Kong: the University of Hong Kong, 2008

35 Chan SY, Wong V. DNA diagnosis of FRAXA and FRAXE in Chinese children with neurodevelopmental disorders and fragile $\mathrm{X}$ syndrome. Clin Genet, 1998, 53: 179-183

36 Wong VC, Lam ST. Fragile X positivity in Chinese children with autistic spectrum disorder. Pediatr Neurol, 1992, 8: 272-274

37 Lam CW, Yeung WL, Ko CH, Poon PM, Tong SF, Chan KY, Lo IF, Chan LY, Hui J, Wong V, Pang CP, Lo YM, Fok TF. Spectrum of mutations in the MECP2 gene in patients with infantile autism and Rett syndrome. J Med Genet, 2000, 37: E41

38 Khong PL, Lam CW, Ooi CG, Ko CH, Wong VC. Magnetic resonance spectroscopy and analysis of MECP2 in Rett syndrome. Pediatr Neurol, 2002, 26: 205-209

39 Wong V, Khong PL. Tuberous sclerosis complex: correlation of magnetic resonance imaging (MRI) findings with comorbidities. J Child Neurol, 2006, 21: 99-105

40 Wong V. Study of the relationship between tuberous sclerosis complex and autistic disorder. J Child Neurol, 2006, 21: 199-204

41 Wong VC, Hughes S. Autism spectrum disorder in children. Med Prog, 2000, 27: 8-16

42 Wong V, Hui LH, Lee WC, Leung LS, Ho PK, Lau WL, Fung CW, Chung B. A modified screening tool for autism (Checklist for Autism in Toddlers [CHAT-23]) for Chinese children. Pediatrics, 2004, 114: e166-176

43 Ng SS, Chow BK, Wong VC. The human secretin gene in children with autistic spectrum disorder: screening for polymorphisms and mutations. J Child Neurol, 2005, 20: 701-704

44 Feuk L, Kalervo A, Lipsanen-Nyman M, Skaug J, Nakabayashi K, Finucane B, Hartung D, Innes M, Kerem B, Nowaczyk MJ, Rivlin J, Roberts W, Senman L, Summers A, Szatmari P, Wong V, Vincent JB, Zeesman S, Osborne LR, Cardy JO, Kere J, Scherer SW, Hannula-Jouppi K. Absence of a paternally inherited FOXP2 gene in developmental verbal dyspraxia. Am J Hum Genet, 2006, 79: 965-972

45 Wong VC, Li SY. Rett syndrome: prevalence among Chinese and a comparison of MECP2 mutations of classic Rett syndrome with other neurodevelopmental disorders. J Child Neurol, 2007, 22: 1397-1400

46 Wong V. Occipital deep white matter hyperintensities in autism spectrum disorder. Pediatr Int, 2007, 49: 513-515

47 Chan AS, Han WMY, Leung WWM, Leungc C, Wongc VCN, Cheungd MC. Abnormalities in the anterior cingulate cortex associated with attentional and inhibitory control deficits: A neurophysiological study on children with autism spectrum disorders. Res Autism Spect Disord, 2011, 5: 254-266

48 Rose L, Wong VCN. Possible effect of acupuncture in autism spectrum disorder. Focus Alternative Compl Ther, 2011 16: 46-48

49 Wong VC, Hui SL. Epidemiological study of autism spectrum disorder in China. J Child Neurol, 2008, 23: 67-72

50 Wong V. Can acupuncture of the tongue help autism? Autism Asper Digest, 2002, 18-19: 25, 29

51 Chen WX, Wu-Li L, Wong VC. Electroacupuncture for children with autism spectrum disorder: pilot study of 2 cases. J Altern Complement Med, 2008, 14: 1057-1065

52 Wong VC, Sun JG. Randomized controlled trial of acupuncture versus sham acupuncture in autism spectrum disorder. J Altern Complement Med, 2010, 16: 545-553

53 Wong VC, Chen WX. Randomized controlled trial of elec- tro-acupuncture for autism spectrum disorder. Altern Med Rev, 2010, 15: $136-146$

54 Cheuk DK, Wong V, Chen WX. Acupuncture for autism spectrum disorders (ASD). Cochrane Database Syst Rev, 2011, 9: CD007849

55 Wong CL. Acupuncture and Autistic Spectrum Disorder-an assessor-blinded randomized controlled trial. Dissertation for Master's Degree. Hong Kong: the University of Hong Kong, 2009

56 Wong VC. Use of complementary and alternative medicine (CAM) in autism spectrum disorder (ASD): comparison of Chinese and western culture (Part A). J Autism Dev Disord, 2009, 39: 454-463

57 Wong VCN, Chu VL. Autism spectrum disorder and traditional Chinese medicine (acupuncture). In: Garralda E, Raynaud J P, eds. Increasing Awareness of Child and Adolescent Mental Health. Jason Aronson: New York, 2010

58 Wong VC, Kwan QK. Randomized controlled trial for early intervention for autism: a pilot study of the Autism 1-2-3 Project. J Autism Dev Disord, 2010, 40: 677-688

59 Wong V. Epilepsy in children with autistic spectrum disorder. J Child Neurol, 1993, 8: 316-322

60 Wong V. Study of the relationship between tuberous sclerosis complex and autistic disorder. J Child Neurol, 2006, 21: 199-204

61 Fung KY. Use of dysmorphology for subgroup classification on autism spectrum disorder in Chinese children. Dissertation for Master's Degree. Hong Kong: the University of Hong Kong, 2010

62 Wong, PTY. Pilot study for subgroup classification for autism spectrum disorder based on dysmorphology and physical measurements in Chinese children. Dissertation for Master's Degree. Hong Kong: the University of Hong Kong, 2012

63 Wong VCN. Autistic disorder in Chinese children. Aust New Zeal J Med, 1991,

64 Wong V, Sun JG, Wong W. Randomized control trial of using tongue acupuncture in children with autistic spectrum disorder. J Neuro Sci, 2001, 187: S329-330

65 Wong V, Sun JG, Ma QY, Yang E. Double blind randomized placebo-controlled trial using tongue acupuncture in children with autistic spectrum disorder. Eur J Neuro, 2001, 5: A82

66 Wong V, Leung C, Sze A. A pilot study of traditional herbal medicine (Gingo Biloba and Ginseng) in two children with attention deficit hyperactivity disorder. Eur J Neuro, 2001, 5: A138

67 Wong V, Sun JG. Research on tongue acupuncture in children with autism. Brain Dev, 2002, 24: 319

68 Yeung D, Wong V, Sun JG. Effect of tongue acupuncture on brain metabolism in autism using brain positron emission tomography. Brain Dev, 2002, 24: 320

69 Fung CW, Wong V, Hui SLH. Autistic spectrum disorders in Hong Kong. Brain Dev, 2002, 24: 330-331

70 Wong V, Lee WC, Leung JLS, et al. Modified checklist for autism in toddlers - third edition (CHAT-3) for Chinese children-Hong Kong Study. Brain Dev, 2002, 24: 331

71 Wong V, Fung CW, Centers-In-Charge of Heep Hong Society. Autism Research Program in Hong Kong: Collaborative Project of Duchess of Kent Children's Hospital (Children's Habilitation Institute) and Heep Hong Society. Brain Dev, 2002, 24: 335

72 Wong V, Lau KS, Hung CN, Shum T, Ngai CF, Ho SI. Identifying prenatal, perinatal and environmental risk factors for autism spectrum disorder (ASD): a case-control study. J Pediatr Neurobio Neurol Neurogenet, 2006, 26: S168

73 Wong PTY. Pilot study for subgroup classification for autism spectrum disorder based on dysmorphology and physical measurements in Chinese paediatric and adolescent population. Abstract presented at Asia Pacific Autism Conference, Perth, Australia, 2011

74 Child Assessment Service, Department of Health, Hong Kong. [2010-10-10]. http://www.dhcas.gov.hk/eindex.html

75 National Autistic Society, on behalf of the National Initiative for Autism: Screening and Assessment (2003). National Autism Plan for 
Children, NAS, London, UK. [2010-10-10]. http://www.autism.org. uk/ /media/NAS/Beta\%20documents/About\%20autism/Autism\%20li brary/Magazines\%20articles\%20and\%20reports/Reports/Other\%20re ports/National\%20Autism\%20Plan\%20for\%20Children $\% 20$ full $\% 20$ r eport.ashx

76 Skuse D, Warrington R, Bishop D, Chowdhury U, Lau J, Mandy W,
Place M. The developmental dimensional and diagnostic interview (3Di): a novel computerized assessment for autism spectrum disorders. J Am Acad Child Adolesc Psychiatry, 2004, 43: 548-558

77 Preece PM, Mott J. Multidisciplinary assessment at a child development centre: do we conform to recommended standards? Child Care Health Dev, 2006, 32: 559-563

Open Access This article is distributed under the terms of the Creative Commons Attribution License which permits any use, distribution, and reproduction in any medium, provided the original author(s) and source are credited. 